\title{
Estado, jurisdição e a participação da sociedade na gestão de políticas públicas
}

\author{
Tássia Aparecida Gervasoni
}

\begin{abstract}
Resumo: O presente trabalho tem como tema as inter-relações entre Estado, jurisdição e políticas públicas. Busca-se analisar a gênese conceitual e a forma de desenvolvimento das políticas públicas, a atual conjuntura de crise do Estado que impossibilita o atendimento das demandas sociais e que conduz à judicialização dessas demandas, apresentando, como alternativa, a partir da estrutura constitucional estabelecida após 1998, a ampliação do espaço público para a inclusão de novos atores sociais, na tentativa de reequilibrar Estado e Sociedade. Em termos de metodologia, utiliza-se um método de abordagem fenomenológico-hermenêutico, métodos de procedimento histórico e monográfico e técnica de pesquisa por documentação indireta, mediante pesquisa bibliográfica. Dentre os resultados encontrados, destaca-se o potencial comunitário para o atendimento com maior qualidade humana e menor custo de algumas demandas sociais, o que poderia reduzir a necessidade de judicialização de determinadas prestações, ao mesmo tempo que fortalecer a autonomia da Sociedade e a democratização do espaço público. Tudo isso, no entanto, não deve servir como pretexto para o afastamento das responsabilidades estatais com relação aos seus deveres constitucionais.
\end{abstract}

Palavras-chave: Estado; Jurisdição; Políticas Públicas; Participação Democrática.

State, jurisdiction and the participation of the society in the management of public politics

\begin{abstract}
The present work has as its theme the interrelationships between State, jurisdiction and public policies. It seeks to analyze the conceptual genesis and the development of public policies, the current crisis of the state that makes it impossible to meet social demands and that leads to the judicialization of these demands, presenting as an alternative, from the constitutional structure established after 1998 , the expansion of public space for the inclusion of new social actors, in an attempt to rebalance State and Society. In terms of methodology, it was used a method of phenomenological-hermeneutical approach, methods of historical and monographic procedure, and technique of research by indirect documentation, through bibliographic research. Among the results found, we highlight the community potential for service with a higher human quality and lower cost of some social demands, which could reduce the need to judicialize certain themes, while strengthening the autonomy of society and democratization of public space. All this, however, should not serve as a pretext for moving away from state responsibilities in relation to their constitutional duties.
\end{abstract}

Keywords: State; Jurisdiction; Public policy; Democratic Participation.

Estado, jurisicción y participación d la sociedad en la gestión de políticas públicas

Resumen: El presente trabajo tiene como tema las interrelaciones entre el Estado, la jurisdicción y las políticas públicas. Busca analizar la génesis conceptual y la forma de desarrollo de las políticas públicas, la actual coyuntura de crisis del Estado que hace imposible satisfacer las demandas sociales y que conduce a la judicialización de estas demandas, presentando como una alternativa, desde la estructura constitucional establecida después de 1998, a la expansión del espacio público para la inclusión de nuevos actores sociales, en un intento por reequilibrar el Estado y la Sociedad. En términos de metodología se utiliza un método de enfoque fenomenológico-hermenéutico, métodos de procedimiento histórico y monográfico, y técnica de investigación por documentación indirecta, mediante investigación bibliográfica. Entre los resultados encontrados, se destaca el potencial comunitario para el atendimiento con mayor calidad humana y menor costo de algunas demandas sociales, lo que podría reducir la necesidad de judicializar determinadas prestaciones, al mismo tiempo que fortalece la autonomía de la sociedad y la democratización del espacio público. Todo esto, sin embargo, no debe servir como pretexto para alejarse de las responsabilidades del estado en relación con sus deberes constitucionales. 
Palabras clave: Estado; Jurisdicción; Políticas Públicas; Participación Democrática.

\section{Introdução}

Dentre os variados sentidos que comporta, a terminologia "política pública" pode ser associada ao resultado material da política, aos instrumentos de atuação do Estado para a realização dos direitos fundamentais. Desse modo, é compreensível que a sua abordagem reclame o exame da própria estrutura estatal para o atendimento das infinitas demandas sociais. Nesse contexto, "crise" é termo que, nos últimos tempos, vem adjetivando Estado, sendo diversas as suas formas de apresentação.

Em crise (sobretudo, financeira), portanto, o Estado vê-se sem condições de realizar todas as previsões constitucionais, o que acarreta a busca pela prestação jurisdicional pelos cidadãos para exigir a realização de muitos de seus direitos por parte do Estado. As políticas públicas passam a ser controladas, a partir de então, pelo Judiciário, o que origina muitos conflitos (de ordem prática e teórica). De qualquer modo, as demandas sociais continuam sem atendimento, pois, não raro, mesmo diante da imposição judicial, o Estado simplesmente não tem recursos para o seu cumprimento.

Todavia, uma alternativa parece estar contemplada já na Constituição Federal de 1988, que ampliou os canais de participação da sociedade na gestão das questões públicas. $\mathrm{O}$ alargamento do espaço público para a inclusão de novos atores sociais na elaboração e efetivação das políticas públicas surge como alternativa viável e democrática para a crise enfrentada pelo Estado.

Assim, o objetivo do presente trabalho é analisar, ainda que brevemente, a gênese conceitual e a forma de desenvolvimento das políticas públicas, a atual conjuntura de crise do Estado que impossibilita o atendimento das demandas sociais e que conduz ao controle judicial das políticas públicas, apresentando, como alternativa, por fim, a ampliação do espaço público para a inclusão de novos atores sociais, na tentativa de (re)equilibrar Estado e Sociedade.

Para tanto, será adotada uma metodologia de abordagem alinhada à fenomenologia hermenêutica, no sentido de apreciar os objetos do estudo "no seu como", no seu "acontecer no mundo". Os métodos de procedimento utilizados serão o monográfico - pelo recorte específico que delimita o texto - e o histórico - por todos os precedentes e influências que serão resgatados como base para compreensão da sociedade atual -. Para completar a metodologia de pesquisa escolhida, utilizar-se-á a técnica de pesquisa da documentação indireta, por meio da pesquisa bibliográfica. 


\section{Fundamentação Teórica}

\subsection{As “crises do Estado" e a judicialização das políticas públicas}

Não é propriamente incomum, em abordagens teóricas, a busca por conceitos, sendo um conceito muito mais que um "nome" atribuído a determinado objeto. Nos conceitos, reúnem-se as ideias nucleares sobre o objeto de estudo, permitindo uma simplificação na sua menção. Por isso, a importância de conceituar e estabelecer os limites, desde logo, do que se pretende denotar ao referir política pública, crise do Estado e judicialização, para que os desdobramentos dessas terminologias ao longo do texto não sejam referências vazias, mas praticamente auto-explicativas.

Primeiramente, em relação às políticas públicas, é preciso advertir que "[...] não se reduzem à implantação de serviços, pois englobam projetos de natureza ético-política e compreendem níveis diversos de relações entre o estado e a sociedade civil na sua constituição" (SCHIMDT, 2008, p. 2310).

Baseado na literatura inglesa, Schimdt dá início a uma interessante abordagem sobre os aspectos conceituais das políticas públicas, estabelecendo-se três diferentes termos para designar distintas dimensões: polity (que se refere à ordem do sistema político, delineada pelo sistema jurídico, e à estrutura institucional do sistema político-administrativo); politics (a cuja dimensão pertencem as questões como as relações entre os poderes executivo, legislativo e judiciário, o processo de tomada de decisão nos governos, as relações entre Estado, mercado e sociedade civil, a competição eleitoral e parlamentar, a atuação dos partidos e forças políticas, etc.); policy (compreende os conteúdos concretos da política, as políticas públicas). Não obstante a separação, na prática, as relações entre polity, politics e policy são permanentes e as influências recíprocas (SCHIMDT, 2008, pp. 2310-2311).

Relativamente à investigação das fases porque passam as políticas públicas, normalmente identificam-se cinco etapas no seu ciclo: percepção e definição de problemas; inserção na agenda política; formulação; implementação e avaliação.

Na primeira fase, há a transformação de um problema social em um problema político. De acordo com Schmidt, "transformar uma situação de dificuldade em problema político é a primeira condição para que uma questão possa gerar uma política pública" (2008, pp. 2310231). Ressalta-se, todavia, que essas dificuldades na sociedade contemporânea são praticamente infinitas, de modo que nem todas serão capazes de mobilizar os esforços políticos, cabendo à imprensa e à própria comunidade, neste sentido, o importante papel de chamar a atenção para esses problemas. 
Quanto a esse aspecto, merece ser destacada a advertência feita por Dowbor, ao ressaltar a importância da organização da sociedade para que se faça ver e ouvir, bem como a necessidade de que seja incentivada a criação de entidades capazes de promover essa organização:

\footnotetext{
o interesse fortíssimo, mas difuso, da população não se transforma em ação concreta, a não ser que as pessoas interessadas numa questão determinada tenham alguém que as represente, faça as pesquisas correspondentes, divulgue a problemática na mídia, saiba fazer uma interpelação jurídica. Assim, a flexibilidade de criação de entidades que nos ajudem a organizar interesses que são difusos mas essenciais, tornou-se vital para o funcionamento da sociedade (DOWBOR, 2008. p. 172).
}

Já na segunda fase, a dificuldade social passa a integrar a agenda política, sendo esta uma espécie de elenco de problemas e assuntos que chamam a atenção do governo e dos cidadãos; ou seja, não se trata de um documento escrito, formal, mas de um rol de questões relevantes debatidas por agentes políticos e sociais e que repercutem fortemente na opinião pública (SCHIMDT, 2008, p. 2316).

A terceira fase é a de formulação, sendo o momento em que se define a maneira de solucionar o problema político em pauta e elegem-se as alternativas a serem adotadas, processando-se nas esferas legislativa e executiva. Conforme Schimdt, "é um momento que envolve conflitos, negociação e acordos entre os agentes com capacidade de decisão (decision-makers) e os grupos sociais interessados", advertindo-se, neste sentido, que "a formulação de uma política pública nunca é puramente técnica. É sempre política, ou seja, orientada por interesses, valores e preferências e apenas parcialmente orientada por critérios técnicos. Cada um dos atores exibe as suas preferências e recursos de poder." Em apertada síntese, pode-se dizer que "a formulação de uma política compreende, ademais, o estabelecimento de diretrizes, objetivos e metas, bem como a atribuição de responsabilidades" (2008, p. 2318). Nessa fase, desenvolvem-se programas e projetos.

Resumidamente, "o processo de formulação de uma política envolve a identificação dos diversos atores e dos diferentes interesses que permeiam a luta por inclusão de determinada questão na agenda política e, posteriormente, a sua regulamentação como política pública" (CUNHA, 2002, p. 15).

Na quarta fase, por sua vez, concretiza-se a terceira, isto é, “a implementação é a fase de concretização da formulação, através de ações e atividades que materializam as diretrizes, programas e projetos, e predominantemente está ao encargo do aparelho burocrático (administrativo)" (CUNHA, 2002, p. 15).

A quinta e última fase consiste no estudo dos êxitos e das falhas do processo de implementação, podendo determinar a continuidade ou a alteração da política pública. Como qualquer avaliação, é um julgamento valorativo. Os aspectos normalmente avaliados são a 
eficácia (resultados obtidos) e a eficiência (relação entre resultado e custo). De qualquer forma, em política, a principal avaliação é sempre eleitoral. Por isso, também, essa fase representa um instrumento democrático, pois capacita o eleitor a exercer certo controle sobre a ação dos governantes (SCHIMDT, 2008, pp. 2319-2321, passim).

De qualquer forma, é possível perceber que "o exame das políticas públicas requer análise sobre o atual estágio de desenvolvimento das formas de atuação do Estado para a realização dos Direitos Fundamentais sociais, econômicos e culturais” (BREUS, 2007, p. 211).

Além disso, fica evidenciada a importância de que se reveste a participação da sociedade em todas as fases que compõem as políticas públicas, desde a elaboração até sua efetivação.

Conforme Breus, "para que o Estado possa influenciar a atuação da sociedade civil, é elaborada uma série de mecanismos jurídicos para que sua atuação ocorra a contento. Nesse contexto, o instrumento utilizado para a promoção dessa participação perante as relações sociais são as políticas públicas" (2007, p. 214).

Num segundo momento, cumpre aclarar o que se pretende, por ora, ao mencionar a "crise do Estado". De imediato, é preciso ressaltar que há certamente muitas manifestações e formas de "crises" - por exemplo, crise econômica, financeira, de legitimidade, de representatividade. Por isso, também, a opção pela nomenclatura no plural (crises do Estado), dada a não pretensão de abordagem profunda e específica de uma determinada manifestação da chamada crise do Estado, embora não se desconheça que a abordagem proposta privilegie o aspecto de crise de representatividade (que leva à discussão do paradigma tradicional de certa oposição entre Estado e cidadão) e de recursos financeiros (que leva ao não atendimento satisfatório de demandas sociais e, corolário, ao controle judicial de políticas públicas, conforme se verá).

De antemão, há que se atentar, aqui, para a complexa e cada vez mais acentuada relação entre poder político e econômico. Neste sentido, Dowbor defende a democratização da economia justamente por considerar o surgimento de um amplo poder político com aspecto de poder econômico, e que, portanto, não pode ser submetido ao controle político, já que, por ser econômico, deveria ser regulado pelas forças de mercado e, assim, acaba controlado por força nenhuma (2008, p. 54).

De fato, atualmente, existem empresas e grupos econômicos cujos orçamentos superam, e em muito, boa parte dos governos de países inteiros, não se podendo ignorar o poder político de que consequentemente revestem-se, com capacidade, inclusive, de sobreporse ao Estado. O cidadão, nesse complexo jogo de forças, que já encontra dificuldades de reportar-se aos próprios representantes políticos e contrapor-se aos entes estatais, fica ainda 
mais afastado dos processos decisórios, cujo centro acaba descolado, não raro, aos grandes (e intangíveis) grupos econômicos.

Esse afastamento entre Estado e cidadão (e também do mercado) na condução da vida pública é, inclusive, apontado como característica central das políticas sociais vigentes no Brasil até os anos 80, que eram marcadas pela exclusão da sociedade civil no processo de formulação das políticas, da implementação dos programas e do controle da ação governamental, inexistindo mecanismos de articulação entre Estado e Sociedade (padrão nãodemocrático) (FARAH, de 2000. pp. 7-8, passim).

Nesse contexto crítico, diz-se que o controle judicial das políticas públicas ${ }^{1}$ surge exatamente da ineficácia do Estado em realizar as políticas públicas segundo as determinações constitucionais, seja em função da limitação decisória decorrente dos mecanismos tradicionais de representação do Estado, seja em decorrência da rediscussão do papel de interferência do Estado na sociedade, que tem o seu papel restringido em vista da redistribuição dos recursos, conforme as determinações de mercado (BREUS, 2009, p. 241).

Não há dúvidas, em relação a outros contornos dados ao Estado pela atual Constituição, sobre a ampliação considerável do âmbito de proteção dos cidadãos, havendo uma ampliação da própria noção e dimensão dos direitos fundamentais e sociais.

Ocorre que essa mudança vem permeada de incertezas e de contradições políticas, jurídicas e sociais, que, na moldura de um Estado Social e Democrático e com uma Constituição material, atribui ao Judiciário algo mais do que dirimir conflitos interindividuais.

Isso significa uma quebra de paradigma, pois se abandona a tradição jurídica individualista e verifica-se um recrudescimento dos direitos fundamentais e da própria Constituição, dos conflitos coletivos, dos deveres do Estado perante o cidadão e, sobretudo, de instrumentos aptos a exigir o cumprimento dessas obrigações.

O cenário exige, de certa forma, um Judiciário atuante, capaz de assegurar a observância à Constituição, ainda que precise impor isso ao Estado, o que abala as estruturas até então estanques que mantinham distantes os Poderes e que afastavam o Judiciário da

\footnotetext{
${ }^{1}$ Sem pretender trazer à tona toda a polêmica doutrinária e jurisprudencial acerca da questão da judicialização das políticas públicas, apresentam-se três correntes que versam sobre o controle judicial das políticas públicas: I) a dos que entendem que o Poder Judiciário possui competência para intervir em políticas públicas sempre que estiver em xeque a efetividade de direitos fundamentais, com maior fundamento na aplicabilidade imediata de tais direitos - artigo $5^{\circ}$, parágrafo $1^{\circ}$, da Constituição Federal; II) a dos que não admitem a referida intervenção, uma vez que as políticas públicas seriam assunto pertinente ao Poder Legislativo e Executivo, cujos agentes estariam legitimados pelo voto popular a realizar o juízo sobre a necessidade e possibilidade de sua implementação, em respeito ao princípio da independência dos Poderes - artigo $2^{\circ}$ da Constituição Federal; e, III) a dos que creem ser possível a intervenção judicial para garantir a integridade e intangibilidade do núcleo consubstanciador de um conjunto irredutível de condições mínimas necessárias a uma existência digna e essenciais à própria sobrevivência do individuo, em observância ao núcleo essencial dos direitos fundamentais a prestações e ao principio da vedação ou proibição do retrocesso social, estando condicionada, contudo, a reserva do possível, isto é, a capacidade econômico-financeira do Estado para a sua imediata implementação (GASTALDI, 2010).
} 
sociedade em geral - o que traz, consequentemente, problemas de outra ordem, como o delicado equilíbrio da interdependência harmônica entre os Poderes.

Como agravante, o Estado já não consegue cumprir com muitos de seus deveres, fazendo com que aumente significativamente a busca da prestação jurisdicional para impor tal cumprimento. Cada vez mais, busca-se o Judiciário para resolver conflitos sociais (individuais ou transindividuais) a que o próprio Estado não consegue dar solução. Busca-se o Judiciário para garantir medicamentos, apela-se ao Judiciário para a obtenção de documentos que permitam a transferência de uma escola a outra de alunos inadimplentes, recorre-se também para buscar proteger o meio ambiente e definir o direito sobre a terra (BARBOSA, 2003. p. 44).

Enfim, não são raros os casos em que se constata a necessidade de uma prestação por parte do Executivo para o cumprimento de uma decisão judicial. Os limites e os riscos da atuação judicial no controle de políticas públicas não são, todavia, objeto do presente trabalho. Aqui, o polêmico fenômeno da judicialização é posto tão-somente como contraponto à crise do Estado, mormente no aspecto financeiro, que o impossibilita de garantir os direitos fundamentais de todos os cidadãos.

Nesse contexto, a doutrina já destaca fortes razões para acreditar-se que a participação do cidadão na vida pública tende a amenizar os problemas até aqui expostos, seja pela possibilidade de organizações da própria sociedade contribuírem com o aparelho estatal no atendimento de demandas sociais (e, assim, diminuir a necessidade de intervenção judicial, por exemplo), seja mediante a aproximação desses âmbitos historicamente dicotômicos (público x privado) que possa otimizar a prestação estatal ou, ao menos, conferir maior caráter democrático às decisões que dizem respeito ao espaço público.

Sugestões para a conformação desse novo espaço de debate, inclusivo e democrático, capaz de aliviar a crise estatal (pelo menos, em alguns pontos) e a intervenção judicial no desenvolvimento de políticas públicas constituem a essência do próximo capítulo a ser explorado.

\section{Fundamentação Teórica}

\subsection{A ampliação do espaço público para a inclusão de novos atores sociais: (re)equilibrando Estado e Sociedade para enfrentar a crise}

Ao tratar-se de ampliação do espaço público, a idéia que exsurge consectária é a de inclusão da sociedade no debate e na vida públicos. Trata-se de arena pública como um novo paradigma, enquanto espaço no qual se desenvolve a atividade pública e o intercâmbio 
Estado-sociedade. Não se trata, portanto, de forma alguma, do rompimento com a figura do Estado, mas da promoção de rearticulação dentro do próprio Estado (BARBOSA, 2003. p. 44).

Constatação no mesmo sentido é feita por Farah, ao afirmar que a inclusão de novos atores sociais na formulação, implementação e controle das políticas públicas, sobretudo no nível local, assinala uma inflexão importante com relação ao padrão de ação do Estado no campo social do país. Desse modo, inicia-se uma ruptura com o padrão não democrático de articulação entre Estado e Sociedade, desenhando-se, ainda que de forma embrionária, uma ampliação do domínio público (2000, p. 21).

Ainda de acordo com Farah, a participação popular constitui uma das dimensões centrais da agenda de Reforma das políticas sociais estabelecida já no início dos anos 80, sendo central a preocupação com a participação do cidadão, considerada crucial para garantir maior universalização e equidade às políticas sociais. Assim, desde o início dos anos 80, são propostos e instituídos mecanismos de gestão de políticas sociais que envolvem a participação popular, como os Conselhos de Saúde e Educação, por exemplo (2000, p. 22).

Ao sustentar a necessidade de modernização do Estado para o desenvolvimento social, Kliksberg defende o incentivo à participação comunitária mediante a reforma do setor social, que deve visar à criação de condições organizacionais que facilitem a participação da comunidade (embora o autor não se negue reconhecer as dificuldades existentes para tanto) (1997, p. 128).

De qualquer forma, considera que

\begin{abstract}
para mobilizar para o setor social público o enorme potencial de colaboração da sociedade civil, com vistas ao atingimento dos objetivos planejados, são necessárias reformas significativas que favoreçam a articulação com as organizações nãogovernamentais e com outras entidades da sociedade civil. Deve-se criar, com a reforma, espaços organizacionais especificamente dedicados a identificar pontos de articulação possíveis e a promover sua articulação [...] (KLIKSBERG, 1997, P. 128).
\end{abstract}

Ocorre que a expansão da sociedade brasileira e o consequente aumento da complexidade das relações sociais, aliada à verdadeira "quebra de paradigma" representada pelo surgimento da Constituição Federal de 1988, que ampliou sensivelmente o âmbito de proteção dos direitos fundamentais, abalou as estruturas organizacionais do Estado, que passou a ser, verdadeiramente, um Estado Democrático de Direito (ao menos, as previsões, esforços e tentativas são nesse sentido).

A Constituição Federal de 1988 (que não à toa é chamada de "Constituição Cidadã") também ampliou as formas de participação social nas questões relativas à vida e às decisões públicas. 
O verdadeiro processo de redemocratização do Estado brasileiro após 1988 consagrou a participação popular na gestão da "coisa pública", ao fundar as bases para que se introduzissem experiências capazes de contribuir para a ampliação da esfera pública, entendida como a arena na qual as questões que afetam a sociedade são expressas, discutidas e tematizadas pelos diversos atores sociais. Esses espaços permitem o exercício do controle político sobre a ação governamental, além de tornarem públicos os interesses dos que o compõem. Essas experiências alteraram significativamente a relação entre Estado e sociedade, uma vez que criaram novos canais de participação popular (CUNHA, 2002, p. 16).

Nesse contexto, afirma-se que as diretrizes constitucionais introduziram um modelo de gestão baseado na descentralização político-administrativa, privilegiando a responsabilidade do Estado e a participação da população na formulação e no controle das ações em todos os níveis de governo (CUNHA, 2002, p. 17).

Evidencia-se, a partir de então, uma preocupação constante com a participação social na formulação e na efetivação das políticas públicas. Se as bases constitucionais preconizam e privilegiam a participação dos cidadãos nas questões relativas às políticas públicas, espera-se que haja, de fato, uma atuação social efetiva, que possa, além de realizar o texto constitucional, contribuir para a melhora das condições da vida social.

Essa redefinição da esfera pública inclui também a construção de novos arranjos institucionais, que superem o modelo de provisão estatal e o padrão uni-organizacional centralizado que caracterizava o período anterior aos anos 80. Tais arranjos apontam para a necessidade de construção de redes institucionais, que reúnam atores diversos, envolvendo articulações intersetoriais, intergovernamentais e articulações entre Estado, mercado e sociedade civil. Tais redes podem (e devem) ser constituídas tanto para a formulação de programas como para a provisão dos serviços públicos. Farah assinala, inclusive, que, na dinâmica recente dos governos locais do Brasil, as políticas públicas sociais já escapam ao modelo tradicional de políticas sociais como atribuição exclusiva do Estado (2000, p. 27).

Descrevendo a lógica que marca a atuação do Estado, do mercado e da sociedade (representada na figura denominada de Terceiro Setor), Dowbor considera que enquanto o Estado tem uma lógica definida pelo direito público administrativo e tem o seu produto contabilizado pelo critério de custo, as empresas operam a partir de outra dinâmica, embora igualmente clara, que é o lucro. O Terceiro Setor perturba essas lógicas, pois: "As suas iniciativas nascem do movimento espontâneo de um grupo de pessoas preocupadas com um problema social que não encontra soluções aparentes nem no Estado, nem na empresa, e que se organizam para dar uma resposta" (2008, p. 171). 
Essa ideia de políticas públicas prestadas pela própria sociedade encontra apoio em Etzioni, para quem "la buena sociedad es la que equilibra tres elementos que frecuentemente aparecen como incompatibles: el estado, el mercado y la comunidad" (2001, p. 17). O autor acredita na sociedade com uma importante fonte de serviços sociais, devendo-se confiar às comunidades uma proporção mais significativa de tarefas, dada a sua capacidade de atendêlas com maior qualidade humana e, inclusive, com menor custo do que em relação ao mercado e ao Estado.

Nessa perspectiva, entende-se que a comunidade não só pode ajudar o Estado na prestação de determinados serviços, como pode fazê-lo, sobretudo, cumprindo mais satisfatoriamente determinadas funções:

\begin{abstract}
según muestran los datos disponibles, las comunidades pueden jugar un papel fundamental en el desempeño de cuidados tanto preventivos como durante los periodos de crisis, reduciendo la necessidad de servicios sociales de financiación pública dedicados a menesteres tan diversos como puedan ser el cuidado de niños, la terapia del dolor o el tratamiento profesional por abuso de drogas o alcoho, así como ayudar en la reducción de la delicuencia juvenil (ETZIONI, 2001, pp. 27-28).
\end{abstract}

Outra vantagem na prestação de determinados serviços pelas comunidades, além da diminuição dos gastos públicos, está numa certa "personificação" das políticas públicas, que, quando efetivadas com a participação da própria comunidade envolvida, corresponde com mais precisão à realidade atendida do que programas governamentais.

A existência de organizações enraizadas nas comunidades e controladas por elas torna a aplicação dos recursos muito mais racional e afinada com as necessidades locais. $\mathrm{O}$ resultado disso é que o dinheiro público assim empregado torna-se muito mais produtivo em termos de resultados práticos para a comunidade (DOWBOR, 2008, p. 174).

A força da organização da sociedade civil, segundo Dowbor, está no fato de que a sua única força vem do apoio social que desperta; ocupa o seu espaço não pela força financeira, ou pela ameaça da multa, mas pelo respeito que merece e, "neste sentido, é um instrumento profundamente democrático que vem complementar de forma essencial os mecanismos tradicionais de gestão social” (DOWBOR, 2008, p. 172).

Para a doutrina especializada parece mesmo não mais haver dúvidas de que "[...] as organizações da sociedade civil constituem um poderoso articulador social, servindo como lastro de bom senso e de racionalidade para um conjunto muito mais amplo de atividades" (DOWBOR, 2008, p. 172), pelo que são cada vez mais indispensáveis.

Com efeito, apresenta-se como promissora a alternativa de inclusão da sociedade no debate e na atuação da vida pública, seja no sentido de minimizar a necessidade de prestação de serviços pelo poder público, avocando para si a responsabilidade pela efetivação de algumas atividades, seja pela racionalização e consequente melhor aproveitamento dos 
recursos públicos destinados a essas atividades. $\mathrm{O}$ atendimento das demandas públicas em níveis mais satisfatórios, por sua vez, pode contribuir para a redução de demandas judiciais, exigindo o cumprimento de determinados serviços, evitando que o Judiciário tenha que se pronunciar a respeito da efetivação das políticas públicas.

\section{Conclusão}

As necessidades sociais que demandam a atuação estatal na sociedade contemporânea são praticamente infinitas. Em contrapartida, os recursos, sobretudo, financeiros, para o atendimento de todas essas demandas são cada vez mais escassos, tornando-se insuficientes. Completando o quadro dramático, a partir da Constituição Federal de 1988 abriu-se caminho para uma atuação judicial intervencionista (ao menos, essa é a realidade brasileira atual), que passa a exercer certo controle sobre as políticas públicas (a chamada judicialização das políticas públicas).

Mas é a própria Carta Magna de 1988 que abre caminhos, também, para a ampliação do espaço público, que reclama a inclusão e a atuação participativa da sociedade em todas as fases porque passam as políticas públicas. Trata-se de (re)equilibrar as relações entre Estado e sociedade.

A atuação da sociedade na vida pública pode minimizar a necessidade de prestação de serviços pelo poder público, ao avocar a responsabilidade pela efetivação de algumas atividades. Ademais, a participação social efetiva contribui para a racionalização e consequente melhor aproveitamento dos recursos públicos destinados a essas atividades. Outro efeito benéfico dessa atuação seria a provável redução de demandas judiciais, exigindo o cumprimento de determinados serviços, evitando que o Judiciário tenha que se pronunciar a respeito da efetivação das políticas públicas e reduzindo, assim, os efeitos da chamada judicialização.

Contudo, importante esclarecer que, de modo algum, a ampliação dos atores sociais na ocupação dos espaços públicos decisórios e mesmo executórios dessas demandas significa uma exoneração ou mesmo diminuição da responsabilidade do Estado com relação aos seus deveres e compromissos constitucionais. Trata-se da defesa da hipótese, aqui, de reforço à ideia de comunidade, tanto no sentido de aprimorar a sua autonomia quanto no sentido de fortalecer a participação democrática em todos os âmbitos que envolvem a execução e o planejamento de políticas públicas.

\section{Referências}


BARBOSA, Claudia Maria. O Supremo Tribunal Federal e as condições de independência do Poder Judiciário brasileiro. Revista da Academia Brasileira de Direito Constitucional. Curitiba, n. 4, jul. 2003.

BREUS, Thiago Lima. Políticas Públicas no Estado Constitucional: problemática da concretização dos direitos fundamentais pela administração pública brasileira contemporânea. Belo Horizonte: Fórum, 2007.

CUNHA, Edite da Penha; M. CUNHA, Eleonora Schettini . Políticas Públicas sociais. In: CARVALHO, Alysson [et. al.] (Org.). Políticas Públicas. Belo Horizonte: UFMG, 2002.

DOWBOR, Ladislau. Democracia econômica: alternativas de gestão social. Petrópolis: Vozes, 2008.

ETZIONI, Amitai. La Tercera Vía hacia una buena sociedad. Propuestas desde el comunitarismo. Madrid: Trotta, 2001.

FARAH, Marta Ferreira Santos. Parcerias, novos arranjos institucionais e políticas públicas locais. Cadernos gestão pública e cidadania. Vol. 18. Abr. 2000.

GASTALDI, Suzana. A implantação de políticas públicas como objeto juridicamente possível da ação civil pública. Disponível em: http://www.academus.pro.br. Acesso em: 8 mai. 2010.

KLIKSBERG, Bernardo. Uma gerência pública para os novos tempos. In: $O$ desafio da exclusão: para uma gestão social eficiente. São Paulo: Fundap, 1997.

SCHIMDT, João Pedro. Para entender as políticas públicas: aspectos conceituais e metodológicos. In: REIS, Jorge Renato dos; LEAL, Rogério Gesta (Org.). Direitos sociais e políticas públicas: desafios contemporâneos. Santa Cruz do Sul: Edunisc, 2008. 